\title{
O ensino da dança e a relação de gênero na educação básica*
}

\section{Dance education and gender ratio in primary education}

Roberta Pereira Feitosa' Celeida Belchior Garcia Cintra Pinto ${ }^{2}$
Recebido em: 26/09/2016

Aprovado em: 23/11/2016.

1 Licenciada em Educação Física e bacharelanda em Educação Física/UNICEUB. robertinhaevans@otmail.com.

2 Pedagoga, formada pela FAFI/Santo Tomas de Aquino, Uberaba-MG, com mestrado em Educação pela UCB/DF. Professora do curso de Educação Física/UNICEUB. celeidacintra@ uol.com.br.

\section{Resumo}

A pesquisa objetivou estudar a dança no ambiente escolar e a relação de gênero entre os alunos, na Educação Física. Foi desenvolvida por meio de uma pesquisa transversal de coleta única de dados, de análise exploratória, utilizando-se dois questionários, um com 03 professores e outro com 24 alunos, com questões fechadas e abertas. Os dados coletados foram analisados por meio do programa estatístico SPSS 22.0. Verificouse que $100 \%$ dos professores trabalham a dança de forma recreativa, enquanto $66,7 \%$ a aplicam para o desenvolvimento de aspectos motores, cognitivos, perceptivos e socioafetivos, o que não foi confirmado pelos alunos. Concluiu-se que a dança não está sendo utilizada nas aulas de Educação Física devido à falta de qualificação dos professores, ausência de espaço adequado e materiais de apoio, ideias sexistas diferenciando a prática e os preconceitos existentes entre os alunos, relacionados a gênero. Palavras-chave: Dança. Relação de Gênero. Educação Física.

\begin{abstract}
The research aimed at studying the dance in the school environment and the gender relationship among the students, in Physical Education. It was developed through a transversal research of single data collection, exploratory analysis, using two questionnaires, one with 03 teachers, and the other with 24 students, with closed and open questions. The data collected were analyzed using the statistical program SPSS 22.0. It was verified that $100 \%$ of the teachers work the dance in a recreational way, while $66.7 \%$ apply it to the development of motor, cognitive, perceptive and socio-affective aspects, which was not confirmed by the students. It was concluded that the dance is not being used in Physical Education classes due to lack of qualification of teachers, absence of adequate space and support materials, sexist ideas differentiating the practice and the existing prejudices among the students, related to gender.
\end{abstract}

Keywords: Dance. Gender relationship. Physical education. 


\section{Introdução}

O exercício de atividades rítmicas pode contribuir, efetivamente, para o desenvolvimento motor, principalmente se for praticado nos primeiros anos escolares, já que nessa fase os aprendizados são mais concretizados. A Educação Física entra como um importante instrumento de potencialização das habilidades motoras (RONDON et al., 2010).

Entre essas atividades rítmicas, a dança é um dos elementos que podem contribuir para o desenvolvimento da criança, em decorrência dos vários estímulos que ela promove como a movimentação corporal e a educação através do ritmo. A dança, também, contribui para o desenvolvimento das capacidades psicomotoras e na organização espaço-temporal, demonstrando sua importância na formação e no domínio de seu corpo (OLIVEIRA et al., 2010).

A dança vem sendo negligenciada dentro das aulas de Educação Física e, ainda, no âmbito escolar, existe a presença de um grande preconceito a respeito do homem estar inserido nessas aulas. O preconceito fica ainda mais evidente quando se trata de alguns estilos de dança, apesar da existência de um rico folclore e da quantidade de danças existentes no país, seu ensino na escola, principalmente para meninos ainda gera bastante preconceito. Uma das maiores dificuldades de implantar a dança no ensino escolar está relacionada à diferença de gênero (PEREIRA; ARRUDA, 2011).

O conceito de gênero não se confunde com o de sexo. O primeiro trata-se de uma condição social de identificação entre masculino e feminino, enquanto o segundo trata-se, apenas, de diferenças biológicas. $\mathrm{O}$ gênero se constrói por meio de um processo social e cultural, fruto da ideia do que pode ser considerado como feminino e masculino. As características de gênero, ao longo do desenvolvimento da pessoa, interferem, diretamente, em sua formação. As diferenças de gênero são construídas e moldadas de acordo com a época vivenciada, podendo-se, assim, questionar o que é masculino ou feminino, se existem formas fixas de se exteriorizar a masculinidade e a feminilidade. (GOELLNER, 2010).

A cultura contemporânea traz a ideia de que os meninos devem explorar as suas habilidades de uma maneira mais ampla se comparado ao que é proporcionado às meninas, já que, para elas, o que é aceito como correto é a sua permanência em casa, geralmente sem tanta movimentação corporal. Outros fatores que criam distinções podem ser verificados no cotidiano como a forma de vestir, os brinquedos oferecidos e a forma de se comportar diante da sociedade, dentre outros. Toda essa diferença poderá ser observada no comportamento e nas habilidades dessas crianças, podendo surgir com isso uma segregação entre os sexos bem como experiências diferentes no meio escolar (ALTMANN et al., 2012).

Podemos verificar essa distinção entre os sexos no estudo feito por Salomão e Maia (2013), que observaram a presença do preconceito na maioria dos alunos, principalmente nos meninos, quando se iniciou as aulas de dança. O preconceito de gênero foi evidente nas aulas e entre os problemas encontrados destacam-se: dificuldade de meninos dançarem com colegas que não tinham intimidade, em dançarem músicas e ritmos que requerem leveza; já as meninas, a dificuldade foi em ter contato corporal com os meninos.

A dança deve ser inserida como uma prática conjunta de meninos e meninas, propiciando as mesmas vivências de movimento para ambos, nas aulas de Educação Física, fundamentada na compreensão de que o movimento não tem sexo, e de que a discriminação tradicional de movimentos para homens e mulheres é construída no processo de socialização das pessoas, sendo atrelada a valores culturais (KUNZ, 2006).

O lugar da dança na escola é assegurado pelos Parâmetros Curriculares Nacionais (1997) e muito se tem discutido sobre sua importância no ambiente escolar como conteúdo da Educação Física, com o objetivo de desenvolver a imaginação, a comunicação não verbal, o pensamento crítico, a autoconfiança, a cooperação e a criatividade, aprimorando o desenvolvimento motor e a consciência corporal, explorando o movimento.

É, também, assegurada na escola, pela Lei de Diretrizes e Bases 9394, mas muitas vezes não está inserida nos diversos contextos educacionais. Ao ser ensinada no contexto escolar, a dança possibilita ao aluno conhecer seu próprio corpo e compreender as relações que são estabelecidas entre fazer, conhecer, interpretar e apreciar a dança (BRASIL, 1996).

Ao contrário, a dança na escola costuma estar desvinculada de um processo comprometido com o ensino e aprendizagem, que deveria contar com a participação efetiva dos alunos, levando-os à compreensão do corpo como construção cultural. Muitas vezes, a dança é vista 
como simples diversão nos intervalos de aulas ou como elemento decorativo em algumas festas de comemoração de datas específicas, porque o professor de Educação Física conhece muito pouco a respeito do que se pode explorar em relação aos seus conteúdos específicos, no contexto escolar (LOMAKINE, 2007).

Apesar de a dança promover uma descoberta corporal e expressiva, além de incluir as realidades sociais, ela, ainda, não está totalmente inserida no ambiente escolar. É necessário mudar a concepção dos professores de Educação Física com relação à dança, uma vez que as tecnologias e o acesso à informação são facilitados, contribuindo para que a dança perca seu caráter apenas festivo ou extracurricular, para ser vista como um conteúdo essencial para a formação integral do individuo (BARBOSA; MOREIRA, 2010).

A dança pode ser trabalha de várias maneiras e o professor deve ter consciência de que não precisa ser um ótimo dançarino, e, sim, um conhecedor da dança-educação, podendo esta ser compreendida como aquela que promove a espontaneidade, a brincadeira, a alegria, tristeza, expressividade, amor, entre outras, trazendo saúde (LIMA; FROTA, 2007).

Nota-se, também, que as escolas, em sua maioria, não possuem um espaço adequado e nem materiais suficientes para o ensino da dança. Essa realidade comprova que deve existir uma maior discussão entre a equipe escolar, com o objetivo de eliminar esses problemas estruturais (SOUSA et al., 2014).

Portanto, com a dança, os alunos podem aprender o respeito, a socialização, a aproximação e amizade, por meio do contato corporal. Não é necessário que o professor seja um especialista para inserir a dança em suas aulas, refletindo sobre os benefícios e as consequências positivas de sua prática na vida dos alunos. É importante entender que as práticas dançantes possuem uma importância para os alunos, aumentando as suas experiências corporais, contribuindo, assim, para a melhoria de todos os aspectos de sua vida, através de uma prática lúdica, divertida e prazerosa (SOUSA; CARAMASCHI, 2011).

Assim, a presente pesquisa teve como objetivo verificar se existe a utilização da prática da dança no ambiente escolar, na Educação Básica - anos finais do Ensino Fundamental e Ensino Médio e se os alunos sentem algum tipo de preconceito nas aulas de dança em relação a gênero.

\section{Materiais e Métodos}

O presente estudo, de caráter transversal de coleta única de análise exploratória, foi realizado com 24 alunos de ambos os sexos, da segunda fase do Ensino Fundamental e do Ensino Médio, na faixa etária entre 11 a 18 anos, de um colégio particular localizado em Brasília- DF, e pelos 3 professores de Educação Física da mesma escola, que estão em exercício da profissão há mais de 1 ano.

Os procedimentos e objetivos do estudo foram informados aos participantes voluntários por meio do Termo de Consentimento Livre e Esclarecido (TCLE), posteriormente devolvido devidamente assinado como requisito para participação no estudo. Este foi submetido ao Comitê de Ética em Pesquisa do Centro Universitário de Brasília - UniCEUB e aprovado com CAAE:48245115.6.0000.0023.

Os instrumentos utilizados neste estudo foram dois questionários juntamente ao Termo de Consentimento Livre e Esclarecido para a coleta de dados, um para os alunos, adaptado de Pereira e Arruda (2011), composto por questões fechadas e abertas (anexo $n^{\circ}$. 01) e outro para os três professores da escola, adaptado de Barbosa e Moreira (2010), com questões abertas e fechadas (anexo $\left.n^{\circ} .02\right)$.

Para análise estatística dos dados, foi utilizado o programa SPSS 22.0 .

\section{Resultados}

\subsection{Questionários dos professores}

Por meio da pesquisa realizada junto aos professores de uma escola particular de Brasília-DF, contamos com a participação de $33,3 \%$ do sexo feminino e $66,7 \%$ do sexo masculino

Questionados sobre as experiências e vivências com a dança, apresentaram os seguintes depoimentos: $66,7 \%$ cursaram a disciplina dança durante a graduação e 33,3\% não tiveram este conteúdo na graduação. $33,3 \%$ participaram de grupos de dança nas escolas em que estudaram enquanto $66,7 \%$ não tiveram essa vivência. 33,3\% participaram ou ainda participam de grupo de dança e $66,7 \%$ não participam como descrito na Tabela 1 . 
Tabela 1 - Frequência de respostas dos professores relacionada aos tipos de experiência/ vivências com a dança

\begin{tabular}{lccc}
\hline & Sim & Não & Total \\
\hline $\begin{array}{l}\text { Cursou disciplina de Dança oferecida } \\
\text { no curso de graduação? }\end{array}$ & $66,7 \%$ & $33,3 \%$ & $100,0 \%$ \\
\hline $\begin{array}{l}\text { Fez parte de grupos de Dança na (s) } \\
\text { escola (s) em que estudou? }\end{array}$ & $33,3 \%$ & $66,7 \%$ & $100,0 \%$ \\
\hline $\begin{array}{l}\text { Participou/ participa de algum grupo } \\
\text { de Dança? }\end{array}$ & $33,3 \%$ & $66,7 \%$ & $100,0 \%$ \\
\hline Fonte: Os autores. & & & \\
\hline
\end{tabular}

Ao serem questionados se aplicavam a dança em suas aulas de Educação Física, todos os professores afirmaram que sim. Diante dessa resposta, perguntou-se como trabalhavam esse conteúdo em suas aulas, devendo assinalar, apenas, as alternativas que mais se identificavam com sua realidade.

Dessa forma, 66,7\% afirmaram trabalhar com a dança direcionada às festividades escolares, enquanto $33,3 \%$ não trabalham com essa finalidade. Todos os professores trabalham esse conteúdo de forma recreativa. $66,7 \%$ a aplicam para desenvolvimento de aspectos motores, cognitivos, perceptivos e socioafetivos e 33,3\% não a aplicam para este fim. Todos a utilizam como conhecimento do corpo e para aproximação/identificação do contexto sociocultural, conforme Tabela 2.

Tabela 2 - Como os professores trabalham a Dança nas aulas de Educação Física? um professor específico para ensinar dança, sendo que $66,7 \%$ não gostam desse conteúdo enquanto $33,3 \%$ gostam (Tabela 3).

Tabela 3 - Motivos que levam os professores a não trabalharem com a dança

\begin{tabular}{lcc}
\hline & Sim & Não \\
\hline Não domina o conteúdo? & $66,7 \%$ & $33,3 \%$ \\
Há resistência dos alunos quanto ao conteúdo? & $66,7 \%$ & $33,3 \%$ \\
Tem professor específico para a dança? & $0,0 \%$ & $100,0 \%$ \\
Não gosta do conteúdo? & $66,7 \%$ & $33,3 \%$ \\
\hline
\end{tabular}

Fonte: Os autores.

Sobre as dificuldades encontradas para trabalhar a dança em suas aulas, 66,7\% afirmam não ter um espaço adequado para o ensino da dança, 33,3\% afirmam que há espaço para seu ensino. Todos alegam não haver recursos e materiais didáticos. Para 33,3\% falta conhecimento/ experiência com o conteúdo, enquanto 66,7\% afirmam ter esse conhecimento/experiência. $66,7 \%$ acreditam não haver interesse/participação por parte dos alunos e 33,3\% discordam, para todos não há incentivo/estimulo por parte da escola (Tabela 4).

Tabela 4 - Dificuldades encontradas para trabalhar a dança nas aulas de Educação Física

\begin{tabular}{|c|c|c|c|}
\hline & Sim & Não & Total \\
\hline Espaço inadequado? & $66,7 \%$ & $33,3 \%$ & $100,0 \%$ \\
\hline $\begin{array}{l}\text { Falta de recursos e materiais } \\
\text { didáticos? }\end{array}$ & $100,0 \%$ & $0,0 \%$ & $100,0 \%$ \\
\hline $\begin{array}{l}\text { Falta de conhecimento/ } \\
\text { experiência com Dança? }\end{array}$ & $33,3 \%$ & $66,7 \%$ & $100,0 \%$ \\
\hline $\begin{array}{l}\text { Falta de interesse/ participação } \\
\text { dos alunos? }\end{array}$ & $66,7 \%$ & $33,3 \%$ & $100,0 \%$ \\
\hline $\begin{array}{l}\text { Falta de incentivo/ estímulo da } \\
\text { escola? }\end{array}$ & $100,0 \%$ & $0,0 \%$ & $100,0 \%$ \\
\hline
\end{tabular}

\subsection{Questionário para os alunos}

Houve uma identificação para saber o sexo e a idade dos alunos participantes: 66,7\% eram do sexo feminino e $33,3 \%$ do sexo masculino. Suas idades variaram entre 11 e 18 anos.

Para uma melhor identificação da existência de um possível preconceito por parte dos alunos, as respostas dadas por eles foram separadas por gênero.

$\mathrm{Na}$ visão das meninas $87,5 \%$ acham que dançar 
não está voltado para o lado feminino e 12,5\% acham que está. 56,3\% afirmaram que existem danças mais femininas e outras mais masculinas e $43,8 \%$ afirmaram que não há, como relacionado na tabela 5 .

$\mathrm{Na}$ justificativa relacionada a danças que seriam mais femininas $43,8 \%$ não justificaram, 25\% citaram o balé, $6,3 \%$ dança do ventre e $25 \%$ acham que a dança é para ambos os sexos, sem diferença. Em relação à justificativa relacionada a danças mais masculinas, $68,8 \%$ não justificaram, 25\% citaram o Hip Hop e $6,3 \%$ o Rap.

Com relação à participação em alguma forma de dança dentro da escola, 43,8\% afirmam que participaram e 56,3\% não participaram. Em relação à justificativa da participação, 12,0\% participaram na festa junina/ quadrilha, $8 \%$ em outras datas comemorativas, $4 \%$ em aulas de artes, $8 \%$ em gincanas, $4 \%$ trote e $64 \%$ não justificaram.

Foi questionado aos alunos se os professores de Educação Física já trabalharam o conteúdo dança em suas aulas e $100 \%$ afirmam que não houve esse tema nas aulas.

Tabela 5 - Respostas do questionário na visão feminina

\begin{tabular}{lccc}
\hline & Sim & Não & Total \\
\hline $\begin{array}{l}\text { Em sua opinião, dançar é } \\
\text { algo mais voltado para } 0\end{array}$ & $12,5 \%$ & $87,5 \%$ & $100,0 \%$ \\
lado feminino? & & & \\
$\begin{array}{l}\text { Existem danças mais } \\
\text { masculinas e outras mais } \\
\text { femininas? }\end{array}$ & $56,3 \%$ & $43,8 \%$ & $100,0 \%$ \\
$\begin{array}{l}\text { Você já participou de } \\
\text { alguma forma de dança } \\
\text { dentro da escola? }\end{array}$ & $43,8 \%$ & $56,3 \%$ & $100,0 \%$ \\
$\begin{array}{l}\text { Seu professor de educação } \\
\text { física já desenvolveu o tema } \\
\text { dança dentro das aulas? }\end{array}$ & $0,0 \%$ & & \\
\hline $\begin{array}{l}\text { Fonte: Os autores. } \\
\text { for }\end{array}$ & & $100,0 \%$ & $100,0 \%$ \\
\hline
\end{tabular}

Sobre a dança no contexto escolar, envolvendo meninos e meninas, apresentaram as seguintes respostas: $8 \%$ não justificou, $20 \%$ acham a dança legal ou uma forma de diversão, $24 \%$ acredita que ajuda no desenvolvimento e que é uma forma de aprendizado, 8\% compreende que deveria ser mais explorado nas aulas de Educação Física, 8\% acha que melhoraria a convivência entre os alunos, $12 \%$ afirmou não ter preconceito e que a dança deveria ser mostrada para ambos os sexos. $4 \%$ compreende que ela deveria estar com- prometida com ensaiar, apresentar e se divertir, $4 \%$ acreditam ser uma forma de aprender sobre cultura, $4 \%$ acham que alguns alunos não participariam e para $8 \%$ é sem graça ou deveria ser uma atividade opcional, conforme tabela 6 .

Tabela 6 - O que pensam sobre dança, no contexto escolar, para meninos e meninas - na visão feminina.

\begin{tabular}{lc}
\hline Respostas & Porcentagem \\
\hline Não justificaram & $8,0 \%$ \\
Acham legal, uma diversão & $20,0 \%$ \\
Ajuda no desenvolvimento/ forma de aprendizado & $24,0 \%$ \\
Deviria ter na aula de educação física, sendo mais explorado & $8,0 \%$ \\
Melhora a convivência entre alunos & $8,0 \%$ \\
Não tem preconceito e que a dança deveria ser mostrada para ambos & $12,0 \%$ \\
os sexos & $4,0 \%$ \\
Deve estar comprometido com ensaiar, apresentar e se divertir & $4,0 \%$ \\
Aprender sobre cultura & $8,0 \%$ \\
Sem graça ou apresentado como atividade opcional & $4,0 \%$ \\
Acham que os alunos não participariam & $100,0 \%$ \\
\hline Total &
\end{tabular}

Fonte: Os autores.

$\mathrm{Na}$ visão dos meninos, de acordo com a tabela 7, $75 \%$ acham que dançar não está voltado para o lado feminino e $25 \%$ acham que está. $75 \%$ afirmaram que existem danças mais femininas e outras mais masculinas e $25 \%$ afirmaram que não há.

Com relação à justificativa sobre as danças que seriam mais femininas, 22,2\% não justificaram, $44,4 \%$ citaram o balé, $11,1 \%$ o pole dance, $11,1 \%$ a zumba e $11,1 \%$ o funk. Na justificativa relacionada às danças mais masculinas $44,4 \%$ não justificaram, $33,3 \%$ citaram o Hip Hop, $11,1 \%$ o arrocha e $11.1 \%$ o sapateado.

Com relação à participação em alguma forma de dança dentro da escola, 25\% afirmam que participaram e $75 \%$ não participaram. Em relação à justificativa da participação, 12,5\% participaram na festa junina/ quadrilha, $12,5 \%$ em aulas de artes, $75 \%$ não justificaram.

Foi questionado aos alunos se os professores de Educação Física já trabalharam o conteúdo dança em suas aulas e $100 \%$ afirmam que não houve esse tema nas aulas. 
Tabela 7 - Respostas do questionário na visão masculina

\begin{tabular}{lccc}
\hline & Sim & Não & Total \\
\hline $\begin{array}{l}\text { Em sua opinião, dançar é algo mais } \\
\text { voltado para o lado feminino? }\end{array}$ & $25,0 \%$ & $75,0 \%$ & $100,0 \%$ \\
$\begin{array}{l}\text { Existem danças mais masculinas e } \\
\text { outras mais femininas? }\end{array}$ & $75,0 \%$ & $25,0 \%$ & $100,0 \%$ \\
$\begin{array}{l}\text { Você já participou de alguma forma } \\
\text { de dança dentro da escola? }\end{array}$ & $25,0 \%$ & $75,0 \%$ & $100,0 \%$ \\
$\begin{array}{l}\text { Seu professor de educação física já } \\
\text { desenvolveu o tema dança dentro } \\
\text { das aulas? }\end{array}$ & $0,0 \%$ & $100,0 \%$ & $100,0 \%$ \\
\hline $\begin{array}{l}\text { Fonte: Os autores. } \\
\text { Pon }\end{array}$ & & & \\
\hline
\end{tabular}

Sobre a dança no contexto escolar, envolvendo meninos e meninas, houve as seguintes respostas: $16,7 \%$ acham a dança legal, motivadora ou uma forma de diversão, 16,7\% compreendem que ajuda no desenvolvimento, na coordenação motora ou que é uma forma de aprendizagem. Para 16,7\% ajuda na melhoria da qualidade de vida. $8,3 \%$ acham que a dança é para todos os sexos e uma forma de demonstrar alegria, 8,3\% entendem que ela deveria ser uma atividade opcional, 8,3\% que é assunto de uma matéria e $8,3 \%$ que a depender do estilo, pode ser uma ótima ideia. Para 16,7\% é uma forma de expressar sentimentos, como descrito na tabela 8 .

Tabela 8 - O que pensam sobre dança, no contexto escolar, para meninos e meninas - na visão masculina

\begin{tabular}{lc}
\hline Respostas & Porcentagem \\
\hline Acham legal, motivadora e diversão & $16,7 \%$ \\
Ajuda no desenvolvimento/coordenação motora/aprendizado & $16,7 \%$ \\
Melhoria da qualidade de vida & $16,7 \%$ \\
É para todos os sexos e uma forma de demonstrar alegria & $8,3 \%$ \\
Atividade opcional & $8,3 \%$ \\
Assunto de uma matéria & $8,3 \%$ \\
Depende do estilo, podendo ser uma ótima ideia & $8,3 \%$ \\
Expressar sentimentos & $16,7 \%$ \\
Total & $100,0 \%$ \\
\hline
\end{tabular}

Fonte: Os autores.

\section{Discussão}

De acordo com os resultados obtidos na pesquisa que teve como um dos objetivos verificar a existência notou-se que não há o ensino da dança nas aulas de Educação Física.

Apesar dos resultados mostrarem que os professores têm ou já tiveram contato com a dança, esses profissionais não aplicam, de forma adequada, em suas aulas, essa temática. A pesquisa de Barbosa e Moreira (2010) confirma esse resultado quando relata que a maioria dos professores já teve alguma vivência com a dança, em especial na graduação.

Já na pesquisa de Sousa et al. (2010), foi observado que o principal agravante para o ensino da dança no ambiente escolar está relacionado à formação inicial, sendo necessário mais atenção na graduação de Educação Física. Um meio para diminuir esse problema seria a implantação de cursos de capacitação, voltados ao ensino da dança, com o objetivo de que os professores de Educação Física tenham um maior contato com as práticas e teorias relacionadas à mesma, adquirindo assim, maior conhecimento para pôr o ensino da dança, em prática, na escola.

Com relação à forma de trabalhar a dança nas aulas de Educação Física, a maioria dos professores alegam que a utilizam para festividades, como forma de recreação, para desenvolvimento de aspectos motores, cognitivos, perceptivos e socioafetivos, como conhecimento do corpo e aproximação do contexto sociocultural dos alunos.

Nesse sentido, Sousa et al. (2014) verificou que a dança está restrita às festividades escolares deixando de lado seu caráter de aprendizado, por não envolver contextos históricos, culturais e sociais. Já Barbosa e Moreira (2010) defendem a necessidade de alterar a concepção dos professores de Educação Física quanto ao ensino da dança, devido ao fato de ser um conteúdo necessário à formação do indivíduo e não apenas uma forma de recreação.

Entre as dificuldades e os motivos para não se trabalhar a dança na escola, destacou-se na pesquisa a falta de domínio e afinidade com o conteúdo, resistência dos alunos, espaço inadequado, falta de recursos e materiais didáticos e falta de incentivo da escola.

No estudo de Silva et al. (2012), foram encontradas as mesmas dificuldades desta pesquisa, porém o autor afirma que os profissionais de Educação Física não devem levar em consideração as suas preferências e sim pensar nos benefícios que a dança proporciona aos alunos.

Ainda em relação a essa temática, Kleinubing et al. (2013), apontam que o professor deve ter a consciência 
que pode ocorrer uma rejeição inicial, pois a princípio é normal os alunos ficarem tímidos ou desconfiados por não conhecerem ou praticar a nova modalidade. Haverá uma maior aceitação quando a dança for inserida mais intensamente na Educação Física, assim como é no futebol, vôlei e no basquete. Afirma que houve interesse por parte dos alunos quanto ao aprendizado da dança, contradizendo esse argumento.

Quanto aos problemas estruturais e materiais Sousa et al. (2014) indicam que a maioria das escolas não oferecem um ambiente propício ao aprendizado da dança, sendo necessário haver discussões e debates com o objetivo de trazer soluções e minimizar esses problemas estruturais.

No que diz respeito à existência de algum tipo de preconceito por parte dos alunos, nas aulas de dança, em relação a gênero, a pesquisa revela que o preconceito seria mínimo entre as meninas, uma vez que a maioria não considera a dança como algo mais voltado para o lado feminino, porém fica evidente a sua existência quando questionadas se há danças mais masculinas ou femininas, pois avaliam o balé como uma dança feminina e o Hip Hop masculino.

$\mathrm{Na}$ opinião dos meninos, o resultado foi semelhante ao das meninas. Eles consideram que a dança não é voltada para o lado feminino, mas que existem danças mais masculinas como o Hip Hop e outras mais femininas como o balé.

No estudo de Pereira e Arruda (2011), os resultados encontrados divergem desta pesquisa em relação aos meninos, em que mais da metade dos alunos afirmaram que a dança é algo voltado para as meninas, evidenciando a existência de preconceito quanto ao gênero, com relação às meninas, onde os resultados foram semelhantes.

Salomão e Maia (2013) explicam, de acordo com os resultados obtidos em sua pesquisa, que os alunos fazem uma diferenciação de gênero para cada estilo de dança e que, a depender do estilo, fica evidenciado o que é permitido para homens e mulheres.

Questiona-se, então, como a escola com características tradicionais pode cooperar para a não diferenciação de gênero. Os professores podem contribuir para o fim da ideia de práticas tidas como exclusivas, eliminando também concepções de que o desempenho escolar esteja ligado a características de gênero, e o fim da linguagem androcêntrica. Os educadores não vão influenciar de forma direta na mudança. Irão, apenas, transmitir ações reflexivas que tragam relações menos hierarquizadas. (OLIVEIRA et al., 2011).

No questionamento quanto à participação dos alunos em alguma forma de dança dentro da escola, mais da metade alegam não terem participado de atividades que envolvam a dança. Os que afirmam terem tido algum contato justificaram essa participação em datas comemorativas como festa junina, gincana e nas aulas de artes, como corrobora o estudo de Sousa et al. (2014), demonstrando que a maioria dos professores não ensinam a dança como instrumento educativo nas aulas de Educação Física, limitando-as a períodos festivos, sem caráter educativo e de aprendizado.

Tal ideia se concretiza quando perguntado aos alunos se os professores de Educação Física já desenvolveram a dança dentro de suas aulas e a totalidade afirma que esse tema nunca foi trabalhado nas aulas, o que contradiz a resposta dada pelos professores, que asseguraram trabalhar a dança na escola. Esse dado é encontrado, também, por Pereira e Arruda (2011), comprovando que os alunos nunca praticaram dança dentro das aulas de Educação Física.

A respeito da dança no contexto escolar, tanto a maioria dos meninos quanto das meninas acham que o seu ensino seria interessante, constituindo-se numa forma de divertimento, que ajudaria no desenvolvimento ou no aprendizado. Para alguns ela melhoraria a convivência entre os alunos, como uma forma de expressar sentimentos e deveria ser trabalhada como atividade opcional. Para a minoria, a dança deveria fazer parte das aulas de educação física.

Essas ideias devem ser consideradas, porém, a dança, no contexto escolar, deve ser compreendida como uma forma de trazer vários benefícios sociais, culturais, cognitivos, motores, contribuindo para a formação corporal e crítica, trazendo autonomia para os indivíduos, entre outros, sendo também um diferencial nas aulas. Tanto os professores quanto os alunos entendem a importância da dança, porém ainda existe uma resistência para a sua aplicação devido aos preconceitos existentes e à formação inadequada na graduação e a falta de espaço adequado para a prática ou falta de afinidade (SILVA et al., 2012).

\section{Considerações Finais}

Observamos por meio dos dados da pesquisa e do referencial bibliográfico que a dança não está sendo 
utilizada nas aulas de Educação Física devido a vários motivos, como: a falta de qualificação dos professores, ausência de espaço adequado e materiais de apoio, ideias sexistas diferenciando práticas de homens e de mulheres, e os preconceitos existentes entre os alunos, relacionados a gênero.

Apesar de os professores terem contato com a dança em sua graduação, eles não a aplicam de forma adequada em suas aulas. É preciso que as instituições de ensino mostrem o real valor da dança no contexto escolar, para que as aulas de Educação Física não fiquem, apenas, no ensino de esportes e possam proporcionar aos alunos o maior número de experiências corporais.

É importante que o professor busque uma qualificação profissional continuada para que ele seja capaz de aplicar vários conteúdos dentro de sua aula, tendo a capacidade de adaptá-los, e, diante da falta de recursos, consiga lidar com os preconceitos existentes.

A escola, como um todo e as aulas de Educação Física são importantes instrumentos para minimizar os preconceitos relacionados às diferenças de gênero e inserir a dança no contexto social do aluno, por ser um ambiente propício a discussões e debates, possibilitando aos alunos criar um senso crítico a respeito desta e das diferenças de gênero, diminuindo, assim, os preconceitos relacionados às diversas práticas corporais.

\section{Referências}

ALTMANN, H. et al. Corpo e movimento: produzindo diferenças de gênero na educação infantil. Pensar a Prática, Goiânia, v. 15, n. 2, p. 272-550, abr./jun. 2012.

BARBOSA, E. A.; MOREIRA, E. C. A dança como conteúdo nas aulas de Educação Física escolar. Coleção Pesquisa em Educação Física, Várzea Paulista, v. 9, n. 1, p. 21-28, 2010.

BRASIL. Ministério da Educação. Secretaria de Educação Básica. Lei de Diretrizes e Bases da Educação Nacional. Brasília: Ministério da Educação, 1996.

BRASIL. Ministério da Educação. Secretaria de Educação Básica. Parâmetros Curriculares Nacionais: Educação Física. Brasília: Ministério da Educação, 1997.

GOELLNER, S. V. A educação dos corpos, dos gêneros e das sexualidades e o reconhecimento da diversidade. Cadernos de Formação RBCE, Santa Catarina, v. 1, n. 2, p. 71-83, mar. 2010.
KLEINUBING, N. D. et al. A dança na perspectiva crítico-emancipatória: uma experiência no contexto do ensino médio. Pensar a Prática, Goiânia, v. 15, n. 3, p. 711728, jul./set. 2012.

KLEINUBING, N. D. et al. A dança no ensino médio: reflexões sobre estereótipos de gênero e movimento. Revista de Educação Física/UEM, Maringá, v. 24, n. 1, p. 71-82, jan./mar. 2013.

KUNZ, E. Didática da Educação Física. Ijuí: Unijuí, 2006.

LIMA, P. R. F; FROTA, M. A. Dança: educação para crianças do ensino público: é possível? Revista Brasileira de Ciência \& Movimento, Brasília, v. 15, n. 3, p. 137-144, 2007.

LOMAKINE, L. Fazer, conhecer, interpretar e apreciar: a dança no contexto da escola. In: SCARPATO, M. (Org.). Educação Física: como planejar as aulas na educação básica. São Paulo: Avercamp, 2007. p. 39-57.

OLIVEIRA, K. et. al. Relações de gênero e educação. Sociais e Humanas, Santa Maria, v. 24, n. 2, p. 101-110, jul./ dez. 2011.

OLIVEIRA, S. A. et al. A importância da dança na melhoria da percepção espacial e temporal em crianças de 4 a 5 anos no Município de Paranavaí-PR. Coleção Pesquisa em Educação Física, Várzea Paulista, v. 9, n. 1, p. 35-42, jan./fev. 2010.

PEREIRA, C. H. N.; ARRUDA, I. E. A. A tematização da dança na escola e sua questão de gênero. Coleção Pesquisa em Educação Física, Várzea Paulista, v. 10, n. 4, p. 21-26, nov./dez. 2011.

RONDON, T. A. et al. Atividades rítmicas e Educação Física escolar: possíveis contribuições ao desenvolvimento motor de escolares de 08 anos de idade. Motriz, Rio Claro, v. 16, n. 1, p. 124-134, jan./mar. 2010. doi: 10.5016/1980-6574.2010v16n1p124

SALOMÃO, A. K.; MAIA, R. A. Enfrentamento do preconceito de gênero no ensino de dança: uma proposta crítico - superadora. 2013. 37 f. Trabalho de Conclusão de Curso (Graduação) - Instituto Federal Sul de Minas Gerais - IFSULDEMINAS, Muzambinho, 2013.

SILVA, M. C. C. et.al. A importância da dança nas aulas de Educação Física - revisão sistemática. Revista Mackenzie de Educação Física e Esporte, São Paulo, v. 11, n. 2, p. 38-54, jul./dez. 2012.

SOUSA, N. C. P. et al. A dança na escola: um sério problema a ser resolvido. Motriz, Rio Claro, v. 16, n. 2, p. 496-505, abr./jun. 2010. doi: 10.5016/1980-6574.2010v1 $6 \mathrm{n} 2 \mathrm{p} 496$ 
SOUSA, N. C. P. et.al. O ensino da dança na escola na ótica dos professores de Educação Física e de Artes. Revista Brasileira de Educação Física e Esporte, São Paulo, v. 28 , n. 3, p. 505-520, jul./set. 2014. doi: 10.1590/180755092014000300505
SOUSA, N. C. P.; CARAMASCHI, S. Contato corporal entre adolescentes através da dança de salão na escola. Motriz, Rio Claro, v. 17, n. 4, p. 618-629, out./dez. 2011. doi: 10.1590/S1980-65742011000400006 